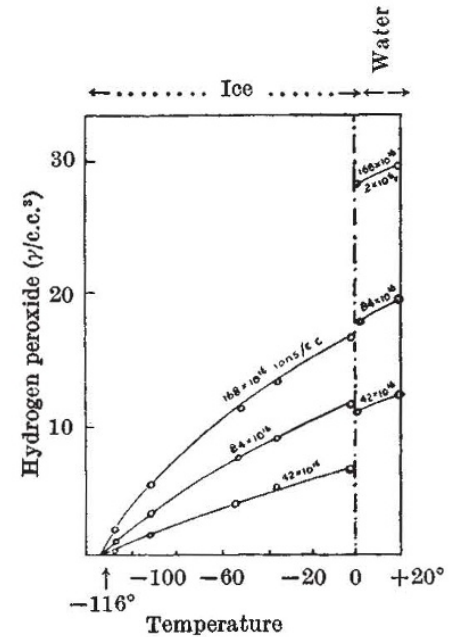

Fig. 3. Influence of temperature. The doses of radiation (reading from the top) are 168,84 and $42 \times 10^{16}$ ions/c.c. for ice; and similarly for water

of course, generally defined as the ratio of the number of molecules decomposed to that of ion pairs produced; this definition is not applicable to hydrogen peroxide formation, because the number of water molecules decomposed is not directly known.)

Temperature Effect. (a) $X$-rays. In oxygen-saturated water, the production of hydrogen peroxide decreases regularly with the temperature, a definite discontinuity marking the passage from water to ice (Fig. 3). Below $-116^{\circ}$, it is no longer possible to detect any hydrogen peroxide, even when the dose is $2 \times 10^{6}$ r. (Fig. 3).

(b) $\alpha$-rays. The temperature seems to be without influence on the production of hydrogen peroxide in water and ice by the $\alpha$-radiation from dissolved radon. At the transition point from water to ice, a discontinuity similar to that of X-rays was observed (Fig. 1). Polonium $\alpha$-rays give similar qualitative results, the catalytic effect of the radio-element being considerably decreased as the temperature is lowered.

Discussion. The experimental results show that hydrogen peroxide is formed according to different mechanisms for $\mathrm{X}$ - or $\alpha$-rays, and that the linear ion density of the radiation affects the primary reactions concerned with the decomposition of the water.

These data are perfectly concordant with the hypothesis suggested by some British workers ${ }^{5}$ for the interpretation of the differences between the radiobiological effects of X-rays and $\alpha$-rays. According to those conceptions, the principal result of the ionization of water is the production along the track of the ionizing particle of hydrogen atoms and hydroxyl radicals (Weiss), the spatial distribution of which corresponds with that of primary ion pairs (Lea and Gray).

For X-rays, the distribution is such that the hydrogen atoms remain near the hydroxyl groups, and, in the absence of oxygen, their recombination to give water is the most likely reaction. When dissolved oxygen is present, the reaction

$$
2 \mathrm{H}+\mathrm{O}_{2}=\mathrm{H}_{2} \mathrm{O}_{2}
$$

becomes possible and produces hydrogen peroxide in amounts which increase with the oxygen concentration and the temperature.

Along the trajectory of an $\alpha$-particle, the hydroxyl groups remain concentrated in the centre of the ionization column and are at first isolated from the hydrogen atoms which form a surrounding sheath. The reaction

$$
\mathrm{OH}+\mathrm{OH}=\mathrm{H}_{2} \mathrm{O}_{2}
$$

is the most likely, and it produces hydrogen peroxide even in the absence of dissolved oxygen; the reaction seems to be independent of the temperature. The constant ionic yield for $\alpha$-rays indicates that, when oxygen is present, the amount of hydrogen peroxide produced according to reaction (1) is negligible com. pared with that produced according to reaction (2).

From these results, it appears that hydrogen peroxide plays an important part in the mechanism of the biological effect of radiations, since its formation seems to be one of the radiochemical primary reactions produced in aqueous media exposed to ionizing radiations.

The remarkable constancy of the ionic yield with $\alpha$-rays shows that the photocolorimetric method is particularly convenient for the radiochemical dosage of dense ionizing radiations such as recoil protons or neutrons.

${ }^{1}$ Bonet-Maury, P., C.R. Soc, Biol., 135, 941 (1941). Latarjet, R., C.R. Acad. Sci., Paris (1942).

'Bonet-Maury, P., and Frilley, M., C.R. Acad. Sci., Paris, 218, 400 (1944).

s Bonet-Maury, P., J. Chem. Phys., (1942).

- Bonet-Maury, P., and Lefort, M., C.R. Acad. Sci., Paris, 220 (1948).

- Lea, "Actions of Radiations on Living Cells" (Camb. Univ. Press, 1945). Weiss, J., Nature, 153, 748 (1944); 15\%, 584 (1946); Trans. Farad. Soc., 11, No. 267 (1944). Allsopp, Brit. J. Radiol.', Supp. No. 1 (1947). Dale, Meredith and Gray (in course of publication).

\section{NATIONAL INSTITUTE OF INDUSTRIAL PSYCHOLOGY}

THE annual conference of the National Institute I of Industrial Psychology was held in Buxton during April 9-12, and a report has now been issued ("Psychology at Work", 1, No. 3 ; July 1948). Welcoming the delegates to the Conference, the chairman of the Institute, General Sir Ronald Forbes Adam, stated that everywhere in industry manage. ment is facing the fact that output must be raised if Britain is to retain its standard of life; but the re-equipping of industry is going to take a long time and some means must be found of achieving the goal more quickly. It has now been generally realized that this increase in output can be achieved if greater attention is paid to human relationships ; but there has been too little research into this problem. The aim of the Conference was to discuss some of the fundamental issues of human relationships, and its purpose can be summed up in three questions: (1) How much knowledge on the subject exists? (2) Is the knowledge readily available and is it being utilized ? (3) What research can be undertaken?

The first session of the Conference was grouped under the heading "The Man and the Job" and, in the first address, Mr. Robert Watsen, chief personnel officer to the Philips group of electrical companies, discussed the selection and allocation of workers. In a recent attempt to check selection and placement practices in industry, Mr. Watson and his colleagues sent out a questionnaire to about two hundred firms in many industries. Replies were obtained from sixty-three firms, including a high proportion of the acknowledged better employers, employing altogether about 300,000 persons. Of the sixty-three firms, four 
employed full-time psychologists ; fifty-two did not give special training to employment interviewers and fifty-three companies did not use job specifications. Forty-eight companies did not give dexterity tests to hourly-paid operators, and fifty-three companies did not give intelligence tests to hourly-paid operators. From this and other data supplied by Mr. Watson it seems reasonably certain that few companies are taking advantage of the latest psychological developments in the use of selection methods. If companies could be persuaded to make use of modern employment practices it would do much to reduce the heavy burden of labour turn-over costs which help to inflate the price of the finished article. While it is not easy to obtain the costs of labour turn-over in any one industry, figures obtained from a firm employing 4,500 females and 3,380 males on mass production work showed that there is a labour turn-over in 1947 of 56 per cent of the total female hourly-paid workers and 38 per cent of the male workers; of those who left the firm during the year, 67 per cent of the women and 72 per cent of the men were in their first year of service.

In a paper on training and working methods, Colonel B. Ungerson, chief psychologist, Directorate of Manpower Planning at the War Office, described the methods which give best results in providing training for unskilled and semi-skilled jobs. Instead of the existing method of placing a newcomer with an experienced operator and telling him to get on with the job, Colonel Ungerson suggested that the efficiency of a department would be considerably improved if newcomers were given definite training under competent instructors. This training should include the presentation of knowledge which would include the most suitable tools for the job, when they were satisfactory for use, what raw materials were used for which jobs and so on. This should be supplemented by as many practical aids as possible, including diagrams, models (or the real thing if possible) and a museum of faults; these should apply both to raw materials and finished products. The problem of developing skill is to ensure a repetition of good movements until they become habitual; this should be based upon movement study and is not necessarily complex. Colonel Ungerson then gave some examples of how skill could be developed in various unskilled and semiskilled jobs.

Following the papers by $\mathrm{Mr}$. Watson and Colonel Ungerson, the Conference divided into eight discussion groups which reported their findings to the Conference at the end of the first day. Summing up the findings of the groups, the chairman, Lord Piercy, said that we are faced with the problem of more production with a given labour force. We can only cut our costs by three means : education, application of what is known, and research. In the field of the education of management we are not yet getting the full benefit out of good practice and, although there will be 'sales resistance' all the way down the management chain, we must get the practice of good firms accepted by others. In the application of particular items of information he was impressed by the stress which has been laid on training as opposed to selection. Training undoubtedly is the key to prompt results, but the individual as a whole should be considered, and here selection is important. On the subject of research it is necessary to pool all our ideas. The problem of the use of individuals of low mentality might profitably be pursued further, and it is pleasing to report that over the last year the Government has come to realize the importance of this work; Panel 3 of the Committee on Industrial Productivity was specially charged with the consideration of the human factors affecting production.

The second session was grouped under the general heading, "The Firm as a Working Unit". Mr. Graham Satow, director of training, Stewarts and Lloyds, Ltd., in a paper on the supervisory grades, traced the development of a changed outlook among workpeople and into this background fitted the position of the foreman and his problems. The same diffculties seem to be encountered on both sides of the Atlantic, and he suggested that the two aims should be to strengthen the foreman's status in the firm and to develop a changed pattern of leadership in the supervisory grades. Mr. Satow then made many practical suggestions as to the methods in which these aims could be realized.

Probably the highlight of the Conference, however, was the paper by Mr. W. L. Mather, director of Mather and Platt, Ltd., on communication within the firm. Borrowing from his experience at the Army Staff College, Mr. Mather gave a practical demonstration of the way in which two-way communication could take place within the firm. Two boards were placed in front of the audience, one of which was marked "Management" and the other "Workers". Between these two there was a gap which, he said, represented the gap between management and workers about which so much was being talked at the present time. The problem is to bridge the gap. Very useful bridges across the gap are provided by personnel departments, works committees, joint production consultative and advisory committees, general committees, training, notice boards, broadsheets, magazines, suggestions schemes, lectures and verbal instructions. These bridges can easily be broken, however, and with a compelling dramatic presentation in which he was helped by a typical British workman, Mr. Mather showed how the only real way of providing communication in any firm is by personal contact.

After further discussion, the second session was summed up by Sir Godfrey Ince, permanent secretary to the Ministry of Labour and National Service, who stated that he was glad that the Conference emphasized the problem caused by the changed outlook of the worker. To find the right relationships between the man and the job involves using the right methods of selection, training and allocation, and use can be made of the Ministry of Labour's experience both with the Juvenile Employment Service and in providing supervisory training through the Training within Industry Scheme.

The final address to the Conference was given by Mr. Austin Albu, deputy director, British Institute of Management, who said that it is the variation between firms which has to be considered when approaching our industrial problems. Some British firms have employed methods which equal those of any other country, and the need is to bring all firms as near as possible to this standard. This can be done, first, by selling ideas to management ; secondly, by breaking down the resistance of trade unions and abolishing restrictive practices generally; and thirdly, by training first-line supervisors. The Conference has profitably discussed ways in which these things can be done, and it is hoped that the British Institute of Management will soon be able to be of direct service to industry.
T. H. HAWKINS 